\title{
Hafnia paralvei sp. nov., formerly known as Hafnia alvei hybridization group 2
}

\author{
Geert Huys, ${ }^{1}$ Margo Cnockaert, ${ }^{1}$ Sharon L. Abbott, ${ }^{2}$ J. Michael Janda ${ }^{2}$ \\ and Peter Vandamme ${ }^{1}$
}

Correspondence

Geert Huys geert.huys@UGent.be
Members of the enterobacterial genus Hafnia are commonly isolated from the gastrointestinal tract of humans and animals (including mammals, birds, reptiles, fish and insects) and from foods (including meat and dairy products) (Janda \& Abbott, 2006). Hafniae are associated with a range of animal infections and have been recovered from human clinical specimens during cases of bacteraemia and gastroenteritis and respiratory tract infections. Their status as primary human or animal pathogens, however, remains controversial because these organisms are usually found together with other pathogens and/or opportunists at the site of infection (Janda \& Abbott, 2006). At present,

Abbreviations: $H G$, hybridization group; rep-PCR, repetitive DNA element-based PCR.

The GenBank/EMBL/DDBJ accession numbers for the 16S rRNA gene sequences of strains ATCC 29926, ATCC 29927 and CCUG 429 are FM179942-FM179944, respectively.

DNA-DNA hybridization data between strains of $H$. alvei $H G 1$ and 2 are available as supplementary material with the online version of this paper.
Hafnia alvei is the only recognized species in the genus Hafnia (Skerman et al., 1980). However, several DNADNA hybridization studies conducted at the Centers for Disease Control and Prevention (CDC) in the 1970s revealed that $H$. alvei is genetically heterogeneous and consists of at least two DNA hybridization groups (HGs) (Brenner, 1978; Steigerwalt et al., 1976). By convention, HG 1 (in some studies also referred to as DNA group 2) represents $H$. alvei sensu stricto as it contains the type strain ATCC $13337^{\mathrm{T}}$, whereas HG 2 was originally delineated using CDC 4360-87 (Steigerwalt et al., 1976), a former reference strain that has not been preserved in the CDC culture collection. In later studies (Janda et al., 2002, 2005; Janda \& Abbott, 2006), other strains, including ATCC 29927, were proposed as alternative reference strains for HG 2. The division of isolates that resemble $H$. alvei phenotypically into HGs 1 and 2 has meanwhile also been substantiated by partial 16S rRNA gene sequencing (Janda et al., 2002, 2005) and multilocus enzyme electrophoresis (Okada \& Gordon, 2003). Although 
biochemical discrimination between the two groups appears to be less straightforward, several potentially useful differential tests have been reported (Janda et al., 2005; Okada \& Gordon, 2003). In the present study, reference strains of $H$. alvei HG 1 (including ATCC $13337^{\mathrm{T}}$ ) and HG 2 (including ATCC 29927) were used in new DNA-DNA hybridization experiments aimed at substantiating the position of HG 1 as $H$. alvei sensu stricto and at allocating members of HG 2 to a novel species. In addition, the potential of repetitive DNA element-based PCR (rep-PCR) fingerprinting as a rapid tool to distinguish the two taxa genotypically was investigated.

A total of 24 reference strains and isolates of $H$. alvei were included in this study (Fig. 1), all of which were characterized phenotypically using conventional biochemical tests as described previously (Janda et al., 2005) except that malonate, aesculin and salicin tests were read for $48 \mathrm{~h}$ and that Darabinose was read for $96 \mathrm{~h}$. In addition to these previously described tests, $\beta$-glucosidase activity was tested using 4methylumbelliferone fluorescent discs (Key Scientific), which were read at $24 \mathrm{~h}$ according to the manufacturer's instructions. Previously, 20 strains were assigned to HG 1 or 2 by partial 16S rRNA gene sequencing (Janda et al., 2002) and included ATCC $13337^{\mathrm{T}}$ (=LMG $10392^{\mathrm{T}}$ ) and ATCC 29926 $(=$ CDC 5632-72=LMG 24702) of HG 1 and ATCC 29927 $(=$ CDC $4510-73=$ LMG 24706) and CCUG 429 (=LMG 24707) of HG 2. The remaining four isolates were isolated from the intestinal tract of Siberian sturgeon (Acipenser baerii) at the Laboratory for Aquatic Ecology, Katholieke Universiteit Leuven (Leuven, Belgium), and were allocated phenotypically to $H$. alvei $\mathrm{HG} 1$ or 2 using conventional biochemical tests (Janda et al., 2005). All isolates were grown routinely on nutrient agar (Oxoid) at $28{ }^{\circ} \mathrm{C}$ (fish isolates) or $37^{\circ} \mathrm{C}$ (clinical isolates) under aerobic conditions.

All isolates were first examined by rep-PCR fingerprinting using the $(\mathrm{GTG})_{5}$ primer, i.e. (GTG) ${ }_{5}$-PCR. DNA extraction,
$(\mathrm{GTG})_{5}$-PCR and data processing were performed essentially as described previously (Gevers et al., 2001). Clustering analysis of $(\mathrm{GTG})_{5}$-PCR band patterns grouped the 20 strains previously characterized by partial $16 \mathrm{~S}$ rRNA gene sequencing into two clusters that were in total agreement with their respective HG designations (Fig. 1). In addition, this grouping also confirmed the allocation of the four sturgeon isolates to their respective HG predicted by conventional biochemical tests. Of these, isolates LMG 24715 and R-25912 (HG 1) displayed identical (GTG) $)_{5}$-PCR fingerprints, indicating that they probably represent the same genotype. These results demonstrate that (GTG) ${ }_{5}$-PCR analysis offers a simple tool to assign genotypically uncharacterized $H$. alvei isolates rapidly to one of the two HGs delineated in the species. Because it allows discrimination at the infraspecific level, the method can also be used to study the epidemiology and environmental distribution of $H$. alvei HGs and to recognize potential replicates among large sets of isolates.

The complete 16S rRNA gene sequence of strain ATCC $13337^{\mathrm{T}}$ was determined previously (GenBank accession no. M59155); sequences of strains ATCC 29926, ATCC 29927 and CCUG 429 were determined in this study. Genomic DNA was extracted as described by Pitcher et al. (1989). Amplification, purification and sequencing were performed according to Vancanneyt et al. (2006). Sequences were aligned using CLUSTAL_X version 1.81 and imported in BioNumerics version 5.1 (Applied Maths) for global cluster analysis. Unknown bases were discarded for analysis. Pairwise comparison of strains ATCC $13337^{\mathrm{T}}$ and ATCC 29926 (HG 1) and strains ATCC 29927 and CCUG 429 (HG 2) revealed 16S rRNA gene sequence similarities of 99.8 and $99.5 \%$, respectively. Between the two groups, sequence similarities ranged from 98.8 to $99.1 \%$. These results confirm previous observations on the basis of partial $16 \mathrm{~S}$ rRNA gene sequencing indicating that HGs 1

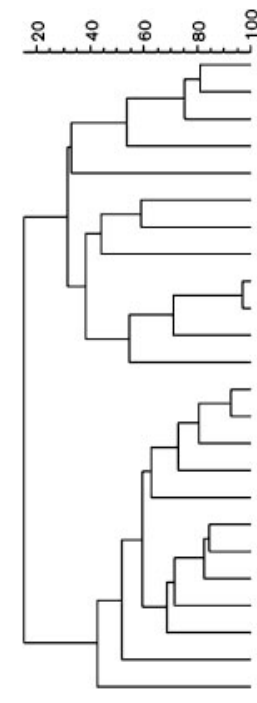

\section{$\stackrel{8}{2}$}

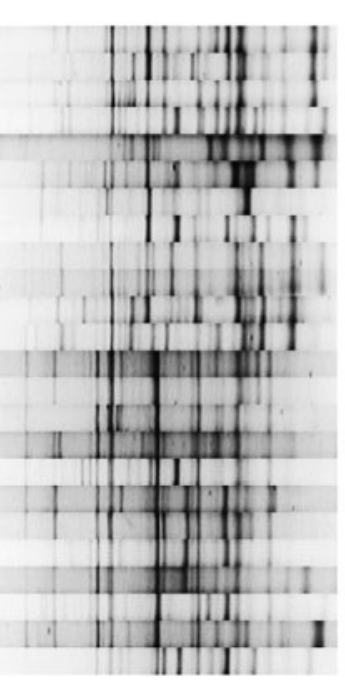

\begin{tabular}{lcl} 
Strain & HG & \multicolumn{1}{c}{ Source } \\
\hline $11419-6-73$ & 1 & Human faeces \\
$2382-8-74$ & 1 & Human faeces \\
ATCC $29926^{*}$ & 1 & Human clinical specimen \\
ATCC $1337^{\top}$ & 1 & Unknown \\
HA-2 & 1 & Unknown \\
$131-004$ & 1 & Unknown \\
$829-7-70^{*}$ & 1 & Human faeces \\
$506-1-72^{*}$ & 1 & Human faeces \\
LMG 24715 & 1 & Sturgeon intestine \\
R-25912 & 1 & Sturgeon intestine \\
D46-NF & 1 & Human faeces \\
$92 A-6500$ & 1 & Human faeces \\
LMG 24717 & 2 & Sturgeon intestine \\
LMG 24716 & 2 & Sturgeon intestine \\
$2199-8-71$ & 2 & Wallaby \\
$84 A-1383^{*}$ & 2 & Human urine \\
ATCC $29927^{*}$ & 2 & Human clinical specimen \\
HA-6 & 2 & Unknown \\
97A-3582 & 2 & Human faeces \\
HA-18 & 2 & Human sputum \\
CCUG 429* & 2 & Human clinical specimen \\
HA-17 & 2 & Human trachea \\
84A-2493 & 2 & Human urine \\
131-009 & 2 & Unknown \\
& &
\end{tabular}

Fig. 1. Dendrogram showing clustering of digitally inverted (GTG) 5 -PCR fingerprints of $24 \mathrm{H}$. alvei reference strains and isolates. The dendrogram was obtained by UPGMA using Pearson's product-moment similarity coefficient (expressed as a percentage). Strains ATCC 29926, 829-7-70, 506-1-72, 84A1383, ATCC 29927 and CCUG 429 (indicated by asterisks) have been deposited in the BCCM/LMG Bacteria Collection (Ghent University, Gent, Belgium; http://bccm. belspo.be/about/lmg.php) as LMG 24702LMG 24707, respectively. HGs were determined previously by partial 16S rRNA gene sequencing (Janda et al., 2002, 2005) except for isolates LMG 24715, LMG 24716, LMG 24717 and R-25912, where HG classification was based on conventional biochemical methods (this study). 
and 2 can be differentiated phylogenetically (Janda et al., $2002,2005)$. In the latter study, sequence divergences of $\leqslant 0.09 \%$ from ATCC $13337^{\mathrm{T}}$ and $\leqslant 0.19 \%$ from ATCC 29927 were reported for members of HGs 1 and 2, respectively. Analysis of the full sequences obtained in the present study, however, suggests that the internal divergence range of HG 2 is somewhat broader, spanning up to $0.5 \%$.

The DNA G $+\mathrm{C}$ contents of $H$. alvei HG 1 strains ATCC $13337^{\mathrm{T}}$ and ATCC 29926 and HG 2 strains ATCC 29927 and CCUG 429 were determined using the enzymic degradation method described by Mesbah et al. (1989). The nucleoside mixture was separated by HPLC using a Waters SymmetryShield C8 column maintained at $37^{\circ} \mathrm{C}$. The solvent was $0.02 \mathrm{M}\left(\mathrm{NH}_{4}\right) \mathrm{H}_{2} \mathrm{PO}_{4}(\mathrm{pH} 4.0)$ with $1.5 \%$ acetonitrile. Non-methylated $\lambda$-phage DNA (Sigma) was used as the calibration reference. The $\mathrm{G}+\mathrm{C}$ contents of HG 1 strains ATCC $13337^{\mathrm{T}}$ and ATCC 29926 were 51.5 and $49.0 \mathrm{~mol} \%$, respectively, and those of HG 2 strains ATCC 29927 and CCUG 429 were 49.8 and $49.2 \mathrm{~mol} \%$, respectively.

To redetermine the relatedness among members of $H$. alvei HGs 1 and 2, DNA-DNA hybridizations were performed using ATCC $13337^{\mathrm{T}}$ and ATCC 29926 as reference strains of HG 1 and ATCC 29927 and CCUG 429 as reference strains of HG 2. Total genomic DNA was prepared using a combination of the protocols of Marmur (1961) and Pitcher et al. (1989) as described previously (Goris et al., 1998). DNA-DNA hybridizations were performed with biotin-labelled probes in microplate wells according to Ezaki et al. (1989) with modifications by Goris et al. (1998) using an HTS7000 Bio Assay Reader (Perkin Elmer) for fluorescence measurements. The hybridization temperature was $37^{\circ} \mathrm{C}$, in the presence of $50 \%$ formamide. Reciprocal experiments were performed for every pair of strains and standard deviations ranged from 1 to $12 \%$. Hybridizations were repeated three times and means of the resulting values were determined. Reciprocal DNA-DNA hybridization values between $H$. alvei strains ATCC $13337^{\mathrm{T}}$ and ATCC 29926 (HG 1) and ATCC 29927 and CCUG 429 (HG 2) were in the ranges $81.7-96.6 \%$ and $74.7-99.9 \%$, respectively (Supplementary Table S1, available in IJSEM Online). Results of cross-hybridizations between the aforementioned members of $H$. alvei HG 1 and HG 2 ranged from 32.7 to $48.7 \%$. In a comparable range, Steigerwalt et al. (1976) reported 51-55\% DNA-DNA binding between members of the two groups. Data from the new DNA-DNA hybridizations thus clearly reinforce these previous observations and, in conjunction with other molecular evidence presented in this study and elsewhere, confirm that the species $H$. alvei consists of at least two HGs. Taking into account the proposed threshold of $\geqslant 70 \%$ DNA-DNA binding to allocate bacterial isolates to the same species (Wayne et al., 1987), it can be concluded that both HGs deserve species status. As suggested previously (Janda et al., 2005), HG 1 corresponds to $H$. alvei sensu stricto because it includes the type strain ATCC
$13337^{\mathrm{T}}$. To accommodate strains formerly classified in $H$. alvei HG 2, a novel species should be created, for which the name Hafnia paralvei sp. nov. is proposed. The former reference strain of $H$. alvei HG 2, ATCC 29927, is designated the type strain of this novel species.

Members of $H$. alvei sensu stricto and the newly proposed $H$. paralvei can be easily differentiated by multilocus enzyme electrophoresis (Okada \& Gordon, 2003) and by DNA-based methods such as (partial) 16S rRNA gene sequencing (Janda et al., 2002, 2005; this study) and (GTG) $)_{5}$-PCR fingerprinting (this study; Fig. 1). Due to the considerable phenotypic heterogeneity among Hafnia strains, which has led to the description of four biotypes (Janda et al., 2002) and the differentiation between typical (clinical) H. alvei and brewery isolates (Farmer et al., 1985), no single biochemical test has so far been reported that is completely discriminatory for $H$. alvei and $H$. paralvei. However, based on a literature survey of several taxonomic studies on the DNA groups of $H$. alvei, Janda \& Abbott (2006) reported cumulative data for 12 phenotypic tests that are useful in distinguishing HG $1(\mathrm{H}$. alvei) and HG 2 (H. paralvei). As a result, it was found that the overall phenotypic profile based on malonate assimilation, aesculin hydrolysis and fermentation of D-arabinose and salicin allows correct assignment of Hafnia isolates to one of the two taxa in $>95 \%(P<0.001)$ of cases (Table 1; Janda et al., 2005). Of these tests, however, only malonate assimilation allows clear-cut differentiation between the two HGs. In a subsequent attempt to find a second fully discriminatory character, a set of 13 Hafnia strains not included in the present study but which were previously allocated to HG 1 or 2 by $16 \mathrm{~S}$ rRNA gene sequencing were tested with the MicroLog 1 System (Biolog) (J. M. Janda and S. L. Abbott, unpublished data). Of the 95 substrates, only two proved useful for separating the two HGs within Hafnia: malonic acid (malonate), which had already been identified as a differential characteristic, and methyl $\beta$-D-glucoside. When the 24 strains included in this study were tested for $\beta$ glucosidase using 4-methylumbelliferone fluorescent discs (Key Scientific), this character was positive for all $H$. alvei

Table 1. Phenotypic differentiation of $H$. alvei and $H$. paralvei sp. nov.

Data for malonate utilization, D-arabinose and salicin fermentation and aesculin hydrolysis were taken from Janda et al. (2005); data for $\beta$ glucosidase were obtained in this study using 4-methylumbelliferone fluorescent discs.,$+ 90-100 \%$ of strains positive; $\mathrm{v}, 16-89 \%$ of strains positive;,$- 0-15 \%$ of strains positive.

\begin{tabular}{|lcc|}
\hline Phenotypic trait & H. alvei & H. paralvei \\
\hline$\beta$-Glucosidase & + & - \\
Malonate utilization & + & - \\
D-Arabinose fermentation & - & $\mathrm{V}$ \\
Salicin fermentation & $\mathrm{V}$ & - \\
Aesculin hydrolysis & $\mathrm{V}$ & - \\
\hline
\end{tabular}


strains (11 strains positive after $24 \mathrm{~h}$ and one positive after $72 \mathrm{~h}$ ), but negative for 10 of the $12 \mathrm{H}$. paralvei strains. In combination with the malonate test, $\beta$-glucosidase thus allows reliable classification of almost $100 \%$ of the Hafnia strains into one of the two species (Table 1).

\section{Description of Hafnia paralvei sp. nov.}

Hafnia paralvei [par.al've.i. Gr. prep. para (also shortened to par) besides; L. gen. n. alvei of a beehive and also a bacterial epithet; N.L. gen. n. paralvei organism similar to H. alvei].

This description is based on data reported previously by Farmer (2003), Janda et al. (2005), Okada \& Gordon (2003) and data from this study. Except where mentioned otherwise, the phenotypic profile of the type strain corresponds to the species description. Gram-negative, oxidase-negative, non-spore-forming, peritrichously flagellated rods. Optimal growth occurs after $24 \mathrm{~h}$ at $28-37{ }^{\circ} \mathrm{C}$ on nutrient agar and various other non-selective nutrientrich media. Facultatively anaerobic, non-pigmented, produces nitrate reductase and positive for the enterobacterial common antigen. Positive for lysine and ornithine decarboxylases. Negative for production of indole and $\mathrm{H}_{2} \mathrm{~S}$, arginine dihydrolase, phenylalanine deaminase, lipase, DNase and degradation of gelatin, mucin and polypectate. Produces acid from D-glucose, L-arabinose, trehalose, maltose, D-mannitol, D-xylose and glycerol, but not from adonitol, amygdalin, D-arabitol, dulcitol, myo-inositol, lactose, melibiose, D-sorbitol, sucrose or methyl $\alpha$-Dglucoside. Most strains (including the type strain) are positive for the Voges-Proskauer reaction, motility, acid production from $\mathrm{D}$-arabinose and hydrolysis of $p$-nitrophenyl $\beta$-galactoside. Strains are negative for either malonate utilization (including the type strain) or $\beta$ glucosidase or both. Together with $H$. alvei, the novel species can be distinguished from other enterobacteria based on lysis by the Hafnia-specific phage 1672 after overnight incubation at $37{ }^{\circ} \mathrm{C}$. Results for tests proposed to discriminate between $H$. alvei and $H$. paralvei are listed in Table 1. Strains have been isolated from human clinical specimens, mammals, reptiles and freshwater fish.

The type strain is ATCC $29927^{\mathrm{T}}\left(=\mathrm{CDC} 4510-73^{\mathrm{T}}=\mathrm{LMG}\right.$ $24706^{\mathrm{T}}$ ), which was isolated from a human clinical specimen. The DNA $\mathrm{G}+\mathrm{C}$ content of the type strain is $49.8 \mathrm{~mol} \%$.

\section{Acknowledgements}

G. H. is a postdoctoral fellow of the Fund for Scientific Research Flanders, Belgium (F.W.O. - Vlaanderen). Tom Vanhoutte, Karolina Lis and Renata Coopman are thanked for their contributions to this study. Amal S. Mahious (Laboratory for Aquatic Ecology, Katholieke Universiteit Leuven, Leuven, Belgium) is thanked for supplying the sturgeon isolates. The orthographical advice of Jean P. Euzéby is highly appreciated.

\section{References}

Brenner, D. J. (1978). Characterization and clinical identification of Enterobacteriaceae by DNA hybridization. Prog Clin Pathol 7, 71-117.

Ezaki, T., Hashimoto, Y. \& Yabuuchi, E. (1989). Fluorometric deoxyribonucleic acid-deoxyribonucleic acid hybridization in microdilution wells as an alternative to membrane filter hybridization in which radioisotopes are used to determine genetic relatedness among bacterial strains. Int J Syst Bacteriol 39, 224-229.

Farmer, J. J., III (2003). Enterobacteriaceae: introduction and identification, pp. 636-653. In Manual of Clinical Microbiology, 8th edn. Edited by P. R. Murray, E. J. Baron, J. H. Jorgensen, M. A. Pfaller \& R. H. Tolken. Washington, DC: American Society for Microbiology.

Farmer, J. J., III, Davis, B. R., Hickman-Brenner, F. W., McWhorter, A., Huntley-Carter, G. P., Asbury, M. A., Riddle, C., Wathen-Grady, H. G., Elias, C. \& other authors (1985). Biochemical identification of new species and biogroups of Enterobacteriaceae isolated from clinical specimens. J Clin Microbiol 21, 46-76.

Gevers, D., Huys, G. \& Swings, J. (2001). Applicability of rep-PCR fingerprinting for differentiation of Lactobacillus species. FEMS Microbiol Lett 205, 31-36.

Goris, J., Suzuki, K., De Vos, P., Nakase, T. \& Kersters, K. (1998). Evaluation of a microplate DNA-DNA hybridization method compared with the initial renaturation method. Can J Microbiol 44, $1148-1153$.

Janda, J. M. \& Abbott, S. L. (2006). The genus Hafnia: from soup to nuts. Clin Microbiol Rev 19, 12-18.

Janda, J. M., Abbott, S. L., Khashe, S. \& Probert, W. (2002). Phenotypic and genotypic properties of the genus Hafnia. J Med Microbiol 51, 575-580.

Janda, J. M., Abbott, S. L., Bystrom, S. \& Probert, W. S. (2005). Identification of two distinct hybridization groups in the genus Hafnia by $16 \mathrm{~S}$ rRNA gene sequencing and phenotypic methods. J Clin Microbiol 43, 3320-3323.

Marmur, J. (1961). A procedure for the isolation of deoxyribonucleic acid from microorganisms. J Mol Biol 3, 208-218.

Mesbah, M., Premachandran, U. \& Whitman, W. B. (1989). Precise measurement of the $\mathrm{G}+\mathrm{C}$ content of deoxyribonucleic acid by highperformance liquid chromatography. Int J Syst Bacteriol 39, 159-167.

Okada, S. \& Gordon, S. M. (2003). Genetic and ecological structure of Hafnia alvei in Australia. Syst Appl Microbiol 26, 585-594.

Pitcher, D. G., Saunders, N. A. \& Owen, R. J. (1989). Rapid extraction of bacterial genomic DNA with guanidium thiocyanate. Lett Appl Microbiol 8, 151-156.

Skerman, V. B. D., McGowan, V. \& Sneath, P. H. A. (editors) (1980). Approved lists of bacterial names. Int J Syst Bacteriol 30, 225-420.

Steigerwalt, A. G., Fanning, G. R., Fife-Asbury, M. A. \& Brenner, D. J. (1976). DNA relatedness among species of Enterobacter and Serratia. Can J Microbiol 22, 121-137.

Vancanneyt, M., Naser, S. M., Engelbeen, K., De Wachter, M., Van der Meulen, R., Cleenwerck, I., Hoste, B., De Vuyst, L. \& Swings, J. (2006). Reclassification of Lactobacillus brevis strains LMG 11494 and LMG 11984 as Lactobacillus parabrevis sp. nov. Int J Syst Evol Microbiol 56, 1553-1557.

Wayne, L. G., Brenner, D. J., Colwell, R. R., Grimont, P. A. D., Kandler, O., Krichevsky, M. I., Moore, L. H., Moore, W. E. C., Murray, R. G. E. \& other authors (1987). International Committee on Systematic Bacteriology. Report of the ad hoc committee on reconciliation of approaches to bacterial systematics. Int J Syst Bacteriol 37, 463-464. 